\title{
Retrospective study to find predictive factors of scar dehiscence in previous caesarean section to prevent maternal and perinatal morbidity and mortality
}

\author{
Natasha Tyagi, Manju Prabhakar*, Smita Tyagi
}

Department of Obstetrics and Gynecology, Muzaffarnagar Medical College, Muzaffarnagar, Uttar Pradesh, India

Received: 22 November 2018

Accepted: 29 December 2018

\author{
*Correspondence: \\ Dr. Manju Prabhakar, \\ E-mail: manju.prabhakar2018@gmail.com
}

Copyright: ( $)$ the author(s), publisher and licensee Medip Academy. This is an open-access article distributed under the terms of the Creative Commons Attribution Non-Commercial License, which permits unrestricted non-commercial use, distribution, and reproduction in any medium, provided the original work is properly cited.

\begin{abstract}
Background: Uterine scar dehiscence is a complication in which scar tissue remaining from previous C-section is disrupted and separated. Its incidence ranges between $0.2 \%-4.3 \%$ of all pregnancies with previous caesarean. It is asymptomatic in $48 \%$ of patients and thus is a serious complication because if not predicted it can lead to uterine rupture.

Methods: Patients included in the study were of previous caesarean who were taken for repeat caesarean and scar dehiscence was not predicted preoperatively but seen intra-operatively. History, symptoms, signs and radiological investigations were interpreted to find out single or multiple factors responsible for scar dehiscence.

Results: Incidence of scar dehiscence was found to be $8.3 \%$.Scar dehiscence was detected in $55 \%$ of cases who were gravida 3 and above, all patients with intraoperative scar tenderness, $35 \%$ of patients with scar thickness $<2 \mathrm{~mm}, 70 \%$ cases with POG $37-40$ weeks, $65 \%$ of patients with interpregnancy interval $<18$ months, $86.6 \%$ of patients with scar dehiscence had baby birth weight $>3 \mathrm{~kg}$.

Conclusions: Authors concluded that a single factor which has maximum predictive value for scar dehiscence is scar tenderness.
\end{abstract}

Keywords: Previous caesarean, Scar dehiscence, Scar tenderness

\section{INTRODUCTION}

Uterine scar dehiscence is a complication of caesarean section in which scar tissue remaining from previous Csection is disrupted and separated. The incidence of this condition ranges between $0.2 \%$ and $4.3 \%$ of all pregnancies with previous caesarean. ${ }^{1}$ It is important to note that scar dehiscence is asymptomatic in $48 \%$ of women and if not taken for LSCS then it will lead to uterine rupture. ${ }^{2-4}$ Thus, scar dehiscence in patients of previous caesarean section is a serious complication because if not predicted it can lead to uterine rupture with serious maternal and perinatal morbidity and mortality.
But it is very difficult to predict scar dehiscence with either individual or a combination of clinical factors. ${ }^{5}$ This study was conducted because we currently lack a method which can reliably predict scar dehiscence. Mostly LSCS is done for some other indication and on opening the abdomen the obstetrician is surprised to see scar dehiscence.

\section{METHODS}

It is a retrospective observational study done in Muzaffarnagar Medical College, Obstetrics and Gynecology department in 2017-2018. In this study 60 
patients were included. These patients were those who were previous one caesarean section and were taken for repeat LSCS either for elective or emergency indication and intraoperative scar dehiscence was detected. These 60 patients were divided into following 3 groups:

\section{Group 1}

20 patients were those who were booked cases with previous one caesarean and were offered elective caesarean section due to some absolute indication like breech, twin pregnancy or short interpregnancy interval.

\section{Group 2}

25 patients were those who were unbooked cases with previous one caesarean section and came to our hospital in labour. At the time of admission these patients were planned for caesarean because of indications like CPD, foetal distress etc.

\section{Group 3}

Rest of the 15 patients were offered VBAC after checking pelvis adequacy:

- 10 went into spontaneous labour

- 5 were induced.

These also had to be taken up for caesarean due to indications like protracted labour, failure of descent, meconium stained liquor or failed induction.

Table 1: Patients included in the study.

\begin{tabular}{|l|l|l|l|}
\hline Group & No. & Details \\
\hline Group 1 & 20 & & Booked patients offered elective LS \\
\hline Group 2 & 25 & & $\begin{array}{l}\text { Unbooked patients who came in } \\
\text { labour and were taken for } \\
\text { emergency LSCS }\end{array}$ \\
\hline Group 3 & 15 & 5 & $\begin{array}{l}\text { Patients offered VBAC and went } \\
\text { into spontaneous labour }\end{array}$ \\
\hline & 10 & $\begin{array}{l}\text { Patients offered VBAC and had to } \\
\text { be induced }\end{array}$ \\
\hline
\end{tabular}

In all these 60 patients scar dehiscence was detected intraoperatively. Authors tried to evaluate the factors responsible for scar dehiscence using detailed history, symptoms, signs and radiological investigations.

The various factors which were studied in relation to scar dehiscence were parity, period of gestation at the time of caesarean, interpregnancy interval, scar tenderness, scar thickness and weight of the baby.

\section{Inclusion criteria}

- Previous one caesarean section

- Any number of previous normal deliveries.

\section{Exclusion criteria}

- Patients with previous 2 or more than 2 caesarean section

- Rupture uterus diagnosed either pre or intraoperatively.

\section{Statistical analysis}

It is a retrospective observational study. Out of 60 patients in whom intraoperative scar dehiscence was detected, data was grouped into those with gravida 2 and above, scar tenderness present or absent, scar thickness $<2 \mathrm{~mm}, \quad 2.1-2.5 \mathrm{~mm}, \quad 2.6-3 \mathrm{~mm}, \quad 3.1-3.5 \mathrm{~mm}, \quad>3.5 \mathrm{~mm}$, $\mathrm{POG}<37$ and $>37$ weeks, interpregnancy interval $<18$ months, 18-24 months, $>24$ months and birthweight $<3 \mathrm{~kg}$ and $>3 \mathrm{~kg}$. Afterwards percentages were calculated of these various categories.

\section{RESULTS}

Incidence of asymptomatic scar dehiscence was $8.3 \%$ in present study in patients with previous one caesarean section. In this study scar dehiscence was detected in $55 \%$ of cases who were gravida 3 and above.

Table 2: Relation of scar dehiscence and gravidity.

\begin{tabular}{|l|l|l|}
\hline Gravida & No. of patients & $\%$ \\
\hline 2 & 27 & 45 \\
\hline 3 and above & 33 & 55 \\
\hline Total & 60 & \\
\hline
\end{tabular}

This shows a close correlation between no. of previous deliveries and scar dehiscence i.e. more the number of previous deliveries, more are the chances of scar dehiscence.

Table 3: Relation of scar dehiscence and scar tenderness.

\begin{tabular}{|l|l|l|}
\hline Scar tenderness & No. of patients & Percentage \\
\hline Present & 60 & 100 \\
\hline Absent & 0 & 0 \\
\hline Total & 60 & \\
\hline
\end{tabular}

Table 4: Relation of scar dehiscence and scar thickness.

\begin{tabular}{|l|l|l|}
\hline Scar thickness $(\mathrm{mm})$ & No. of patients & Percentage \\
\hline$<2$ & 21 & 35 \\
\hline $2.1-2.5$ & 19 & 31.66 \\
\hline $2.6-3.0$ & 13 & 21.66 \\
\hline $3.1-3.5$ & 4 & 6.66 \\
\hline$>3.5$ & 3 & 5 \\
\hline
\end{tabular}

In present study scar tenderness was present in all the patients who had intraoperative scar dehiscence. This proves that scar tenderness is a very strong predictive 
factor of scar dehiscence and should be taken very seriously.

In present study scar dehiscence was seen in $35 \%$ of patients when scar thickness is less than $2 \mathrm{~mm}$ and only $5 \%$ of patients had scar dehiscence when scar thickness was more than $3.5 \mathrm{~mm}$.

Table 5: Relation of scar dehiscence and period of gestation.

\begin{tabular}{|l|l|l|}
\hline POG & $\begin{array}{l}\text { No. of } \\
\text { patients }\end{array}$ & Percentage \\
\hline Up to 36 weeks 6 days & 18 & 30 \\
\hline 37 weeks-40 weeks & 42 & 70 \\
\hline
\end{tabular}

This shows that lesser is the scar thickness detected on preoperative ultrasound more is the risk of scar dehiscence in the patient.

Table 6: Relation of scar dehiscence and interpregnancy interval.

\begin{tabular}{|l|l|l|}
$\begin{array}{l}\text { Interpregnancy } \\
\text { interval }\end{array}$ & No. of patients & Percentage \\
\hline$<18$ months & 39 & 65 \\
\hline $18-24$ months & 17 & 28.33 \\
\hline$>24$ months & 4 & 6.66 \\
\hline Total & 60 & \\
\hline
\end{tabular}

In this study scar dehiscence was present in $70 \%$ cases in the gestational age of 37-40 weeks and only in 30\% cases with gestational age up to 36-week 6days. This shows that as the gestation approaches term and beyond, more are the chances of scar dehiscence.

\section{Table 7: Relation of scar dehiscence and birth weight.}

\begin{tabular}{|l|l|l|}
\hline Birth weight & No. of patients & Percentage \\
\hline$<3 \mathrm{~kg}$ & 8 & 13.3 \\
\hline$>3 \mathrm{~kg}$ & 52 & 86.6 \\
\hline
\end{tabular}

In this study $86.6 \%$ of patients with scar dehiscence had baby birth weight more than $3 \mathrm{~kg}$ and only $13.3 \%$ patients had baby birth weight less than $3 \mathrm{~kg}$. If the weight of the baby is more, more are the chances of scar dehiscence.

\section{DISCUSSION}

Incidence of scar dehiscence was $8.3 \%$ in present study. Baron $\mathbf{J}$ et al, in their study done in 2014 predicted incidence of scar dehiscence between $0.2 \%$ and $4.3 \% .^{1}$ In this study the increased incidence of scar dehiscence could be ascertained to the fact that being a developing country, antenatal services have not yet reached out to rural areas due to poverty and illiteracy. So careful decision whether VBAC can be tried or not is not taken beforehand and patients report to the hospital when labour sets in and scar dehiscence has already taken place. Various factors which were studied to predict scar dehiscence include gravidity, period of gestation, interpregnancy interval, scar tenderness, scar thickness and weight of the baby.

Scar dehiscence was observed in $55 \%$ of patients who were gravida 3 and above (Table 2). This shows a close correlation between no. of previous deliveries and scar dehiscence. This can be explained by the thinning of myometrium due to successive pregnancies.

Also, it was seen that all patients in which scar tenderness was elicited at the time of taking decision for LSCS, had scar dehiscence intraoperatively (Table 3).

Thus, according to present study scar tenderness is the single most important predictor of scar dehiscence. If scar tenderness is present the patient should be taken for emergency caesarean section, especially if it is associated with other predictive factors.

In this study $35 \%$ of patients with scar dehiscence had scar thickness less than $2 \mathrm{~mm}$ and only $5 \%$ of patients with scar dehiscence had scar thickness more than $3.5 \mathrm{~mm}$ (Table 4). This shows that lesser the scar thickness more the chances of scar dehiscence.

There have been various studies in which people have tried to find a value of scar thickness which is safe for VBAC. N Singh et al, in their study in 2015 found that scar thickness less than $2 \mathrm{~mm}$ in third trimester was associated with scar dehiscence. ${ }^{6}$ Ejub Basic et al, in their study in 2012 found the cut off thickness of previous caesarean scar to be $3.5 \mathrm{~mm}$ for allowing a successful vaginal delivery. ${ }^{7}$ Sen $\mathrm{S}$ et al, found the critical cut off value for safe lower segment thickness to be $2.5 \mathrm{~mm} .{ }^{8}$

In present study scar dehiscence was present in $70 \%$ cases in the gestational age of $37-40$ weeks and $30 \%$ in the gestational age below 37 weeks (Table 5). Hence it can be safely concluded that more the gestational age after 37 weeks, more the chance of scar dehiscence.

This is in accordance with Fukuda $\mathrm{M}$ et al, who in their study done in 2015 found out that lower uterine segment thickness decreases with gestational age and correlates strongly with intraoperative lower uterine segment thickness in women with previous caesarean section. ${ }^{9}$ Although Ram M et al, in 2018 found in their study that gestational age at delivery was not found to be an independent risk factor for the success of VBAC. ${ }^{10}$

In present study scar dehiscence was reported in $65 \%$ of patients with interpregnancy interval less than 18 months and in only $6.66 \%$ of patients with interpregnancy interval more than 24 months (Table 6). A longer time interval after a previous caesarean section gives more quality attributes to the scar. ${ }^{7}$ This is in close correlation to the study by Valentin L in 2013. ${ }^{11}$ They studied predictive factors of scar dehiscence and reported statistically significant association of uterine rupture with 
various variables-underdeliver interval (higher risk with short interval), birth weight (higher risk if 4000gm or more) and previous vaginal delivery(lower risk).

Authors also found out in present study that scar dehiscence was present in $86.6 \%$ of patients with birth weight more than $3 \mathrm{~kg}$ and only in $13.3 \%$ of patients with birth weight less than $3 \mathrm{~kg}$ (Table 7). This strongly indicates that more the weight of the baby more the chances of scar thinning and hence scar dehiscence. Jastrow $\mathrm{N}$ et al, in their study in 2010 found out that birth weight of $4 \mathrm{~kg}$ or more is associated with uterine rupture, failed trial of labor, shoulder dystocia and third- and fourth-degree perineal laceration. ${ }^{2}$

Also, authors devised a scar dehiscence score using all the six parameters studied i.e. gravidity index, scar tenderness, period of gestation, interpregnancy interval, scar thickness and birth weight. Score was calculated as follows:

\section{Table 8: Scar dehiscence score.}

\begin{tabular}{|l|l|}
\hline Predictive factors of scar dehiscence & Score \\
\hline Scar tenderness & 4 \\
\hline $3^{\text {rd }}$ gravida and above & 2 \\
\hline Scar thickness $\leq 2.5 \mathrm{~mm}$ & 2 \\
\hline POG $37-40$ weeks & 2 \\
\hline Interpregnancy interval $<18$ months & 2 \\
\hline Birth weight $>3 \mathrm{~kg}$ & 2 \\
\hline
\end{tabular}

It was seen that scar tenderness was present in $100 \%$ cases of scar dehiscence, $55 \%$ cases of $3^{\text {rd }}$ gravida and above, $66.66 \%$ of cases with scar thickness $\leq 2.5 \mathrm{~mm}, 70 \%$ in 37 to 40 weeks, $65 \%$ in $\leq 18$ months of interpregnancy interval, $86.6 \%$ in birth weight of $3 \mathrm{~kg}$ and more.

Authors concluded that a single factor which has maximum predictive value for scar dehiscence is scar tenderness. Regarding the score it is safe to assume that if score is 6 or more, then the patient should be taken for caesarean section to prevent scar dehiscence. This means that if along with scar tenderness, one more factor is present then the patient should be taken up for caesarean section.

\section{CONCLUSION}

This study was done to find out the predictive factors of scar dehiscence in cases of previous caesarean and the aim of this research is early diagnosis of scar dehiscence to prevent scar rupture, thus decreasing maternal and foetal morbidity.

Factors which should be considered regarding prevention of scar dehiscence and preventing maternal and foetal morbidity are social, clinical and diagnostic.

Regarding social factors, patient should be counselled about regular antenatal care, proper contraception for interval between two pregnancies and ultrasound evaluation for scar thickness, especially in third trimester.

Regarding clinical factors, labour monitoring in such high-risk patients should be done intensively under the guidance of a senior obstetrician to detect early signs of scar dehiscence.

Regarding diagnostic factors, more research should be done in the field of ultrasound and MRI evaluation of the scar so that impending dehiscence can be picked up beforehand and patient is not allowed VBAC to prevent maternal and foetal morbidity.

\section{Funding: No funding sources \\ Conflict of interest: None declared}

Ethical approval: The study was approved by the Institutional Ethics Committee

\section{REFERENCES}

1. Baron J, Weintraub AY, Eshkoli T, Hershkovitz R, Sheiner E. The consequences of previous uterine scar dehiscence and cesarean delivery on subsequent births. Int J Gynaecol Obstet. 2014;126(2):120-2.

2. Royal College of Obstetricians and Gynaecologists. Birth after previous caesarean birth. Green-top guideline. 2007(45).

3. Health and Social Care Information Centre. NHS Maternity Statistics - England, April 2012 to March 2013: Provider level analysis. [Leeds]: HSCIC; 2013 Available at: http://www.hscic. gov.uk/catalogue/PUB12744.

4. Welsh Government. Maternity Statistics, Wales: Method of Delivery, 2004-2014. SDR 210/2014. Cardiff: Welsh Government;2014 Available at: http:/gov.wales/docs/statistics/2014/141202maternity-method-delivery-2014-en. pdf.

5. Macones GA, Cahill AG, Stamilio DM, Odibo A, Peipert J, Stevens EJ. Can uterine rupture in patients attempting vaginal birth after cesarean delivery Be predicted? Am J Obstet Gynecol. 2006;195(4):114852.

6. Singh N, Tripathi R, Mala YM, Dixit R. Scar thickness measurement by transvaginal sonography in late second trimester and third trimester in pregnant patients with previous cesarean section: does sequential change in scar thickness with gestational age correlate with mode of delivery? J Ultrasound. 2015;18(2):173-8.

7. Basic E, Basic-Cetkovic V, Kozaric H, Rama A. Ultrasound evaluation of uterine scar after caesarean section. Acta Informat Medica. 2012;20(3):149-53.

8. Sen S, Malik S, Salhan S. Ultrasonographic evaluation of lower uterine segment thickness in patients of previous cesarean section. Int J Gynaecol Obstet. 2004;87(3):215-9.

9. Fukuda M, Fukuda K, Shimizu T, Bujold E. Ultrasound Assessment of Lower Uterine Segment Thickness During Pregnancy, Labour, and the 
Postpartum Period. J Obstet Gynaecol Can. 2016;38(2):134-40.

10. Ram M, Hiersch L, Ashwal E, Nassie D, Lavie A, Yogev Y, et al. Trial of labor following one previous cesarean delivery: the effect of gestational age. Arch Gynecol Obstet. 2018;297(4):907-913.

11. Valentin L. Prediction of scar integrity and vaginal birth after caesarean delivery. Best Pract Res Clin Obstet Gynaecol. 2013;27(2):285-95.

12. Jastrow N, Roberge S, Gauthier RJ, Laroche L, Duperron L, et al. Effect of birth weight on adverse obstetric outcomes in vaginal birth after cesarean delivery. Obstet Gynecol. 2010;115.

Cite this article as: Tyagi N, Prabhakar M, Tyagi S. Retrospective study to find predictive factors of scar dehiscence in previous caesarean section to prevent maternal and perinatal morbidity and mortality. Int $\mathrm{J}$ Reprod Contracept Obstet Gynecol 2019;8:531-5. 